\title{
The epidemiology of fatigue: more questions than answers
}

\author{
G Lewis, S Wessely
}

Fatigue syndromes, though recognised for some time, have recently attracted a variety of new diagnostic labels, as well as both professional and media controversy. However, most of the arguments surround the interpretation of small hospital based case-control studies using highly selected groups of patients. ${ }^{1}$ There is relative silence on population based studies, which perhaps contributes to the lack of concensus. This paper reviews the epidemiology of fatigue in the general population and in primary care and examines potential sources of bias in hospital based studies.

\section{Fatigue: definition and assessment}

After the Great War, an Industrial Fatigue Board was formed, in part to search for the holy grail of an objective test for fatigue. It reported in strong terms, ${ }^{2}$ demanding "that the term fatigue be absolutely banished from precise scientific discussion, and consequently that attempts to obtain a fatigue test be abandoned". Similar disillusionment since $^{34}$ was largely due to a realisation that fatigue was a subjective experience that could not be measured by objective methods.

There is now greater readiness to rely on subjective reports in medicine, what Feinstein ${ }^{5}$ has called "the basic element of medical communication ... direct descriptions of sensations", and less emphasis on the elusive definitive fatigue test. Unfortunately, there has been little standardisation of fatigue measurement between studies, so hindering comparisons. Most survey data are based on the answers to a single question on fatigue, the wording of which can introduce substantial differences between studies. Complaints of feeling "tired out all the time" are nearly 10 times more commoner than feeling "weak" (L Robins, personal communication, and ${ }^{7}$ ), while "general fatigue" is twice as common as exhaustion. ${ }^{7}$ Recent studies have suggested that although there may be a single construct underlying the various synonyms adopted by patients to describe physical fatigue (which may be distinct from that for mental fatigue), wide variations may result if only a single symptom is being assessed. ${ }^{89}$ Of particular relevance to the following discussion is the finding that of 16 adjectives used by psychiatrists to signify sadness, six were applied by patients to states of fatigue. ${ }^{10}$

The measurement of fatigue will therefore hinge closely upon the interpretation of particular words by respondents, and the cultural and linguistic heritage should also be considered when attempting to explain population differences.

Two particular areas need further exploration. First, although we shall later support a dimensional view of fatigue, it is probable that it is multidimensional. Fatigue has emotional, behavioural, and cognitive components, whose relationship remains unexplored. ${ }^{11}$ Also unexplored are the concepts of fatigue (a subjective sensation) and fatigability (onset of symptoms after exertion), which have both different meanings and pathophysiology. Thus we repeat an earlier plea for more precise information on the phenomenology of fatigue. ${ }^{9}$

Fatigue: symptom or syndrome?

The chronic fatigue syndrome $(\mathrm{CFS})^{12}$ is usually applied to those patients with excessive fatigability without an adequate medical explanation. Other diagnostic labels have been used, and probably refer to the same group of patients; these include "post viral fatigue syndrome" and "myalgic encephalomyelitis", which are both commonly used in the UK, and "chronic Epstein-Barr virus infection" which is still used in North America. ${ }^{13}$ All these alternatives imply a greater knowledge and understanding of the causes of chronic fatigue than is justified.

Community surveys have repeatedly shown that complaints of fatigue are extremely common in developed countries (table I). The prevalence of fatigue was $14.3 \%$ in men and $20.4 \%$ in women in the US Health and Nutrition Examination Survey, ${ }^{14}$ and although the vast majority of complaints of tiredness are never brought to medical attention, ${ }^{15} 16$ "tiredness and exhaustion" are still responsible for over two million visits to US internists each year. ${ }^{17}$ What is the relationship between the mild, frequent complaints of fatigue seen in the community and the severe, disabling fatigue characteristsic of CFS?

Fatigue, like many medical conditions, is best viewed as a continuum. In Geoffrey Rose's words "the real question in population studies is not 'Has he got it?' but 'How much of it has he got?" ". ${ }^{18}$ David et $a l^{9}$ found a continuous distribution of fatigue scores among attenders in primary care, with no cut off or point of rarity. Unpublished data collected during the 1987 US General Social Survey (C R Cloninger, personal communication) which included 10 questions on 
Table I Community studies

Table II Primary care studies fatigue, tiredness, need to rest, and the rate of recovery from viral infections, ${ }^{19}$ can be used to show a similar pattern for fatigue related symptoms in the population. Seventy eight percent of of women and $73^{\circ}$ o of men endorsed at least one item, confirming that some degree of fatigue is found in nearly all the population. The mean number of items endorsed was 2.08 (males) and 2.75 (females), but only $0.5 \%$ of males and $1.0 \%$ of females agreed with all 10 items, indicating very severe fatigue (figure).

We suggest that many patients currently labelled as having "chronic fatigue syndrome" may not be cases of a discrete disorder, but instead may lie at the extreme end of a continuum that begins with the common feeling of tiredness described in community surveys. The situation is reminiscent of the Platt/Pickering debate on the nature of hypertension. ${ }^{20}$

Fatigue in the community

What is known about the associations of fatigue in the population? Most, but not all, studies, find complaints of fatigue to be between two or three times more prevalent in women than men (table I and II)-the more homogeneous the study, the less the difference. ${ }^{21}$ Although some have found this difference to be explained by higher rates of psychiatric disorder among women, ${ }^{14}$ this has not been confirmed. ${ }^{22}$ An alternative explanation is that differences in duration may explain some of this increased prevalence: in one study the mean duration of fatigue was 10.6 years in women, but 7.9 in men. ${ }^{23}$ Studies reveal no consistent variation with age, except that fatigue is uncommon before adolescence. ${ }^{24} 25$

Most physical illnesses are associated with fatigue. For example, Chen ${ }^{14}$ calculated the odds ratios for fatigue associated with certain chronic diseases, namely anaemia, emphysema, asthma, and arthritis, and found values of between 1.9 and 2.9; similar results have been seen in a United Kingdom study. ${ }^{22}$ Recent data also suggest an association between tiredness and low blood pressure. ${ }^{26}{ }^{27}$ Psychiatric disorders are even more highly associated with fatigue, with odds ratios between 3 and $6 .{ }^{1422} 28$ Fatigue is also associated

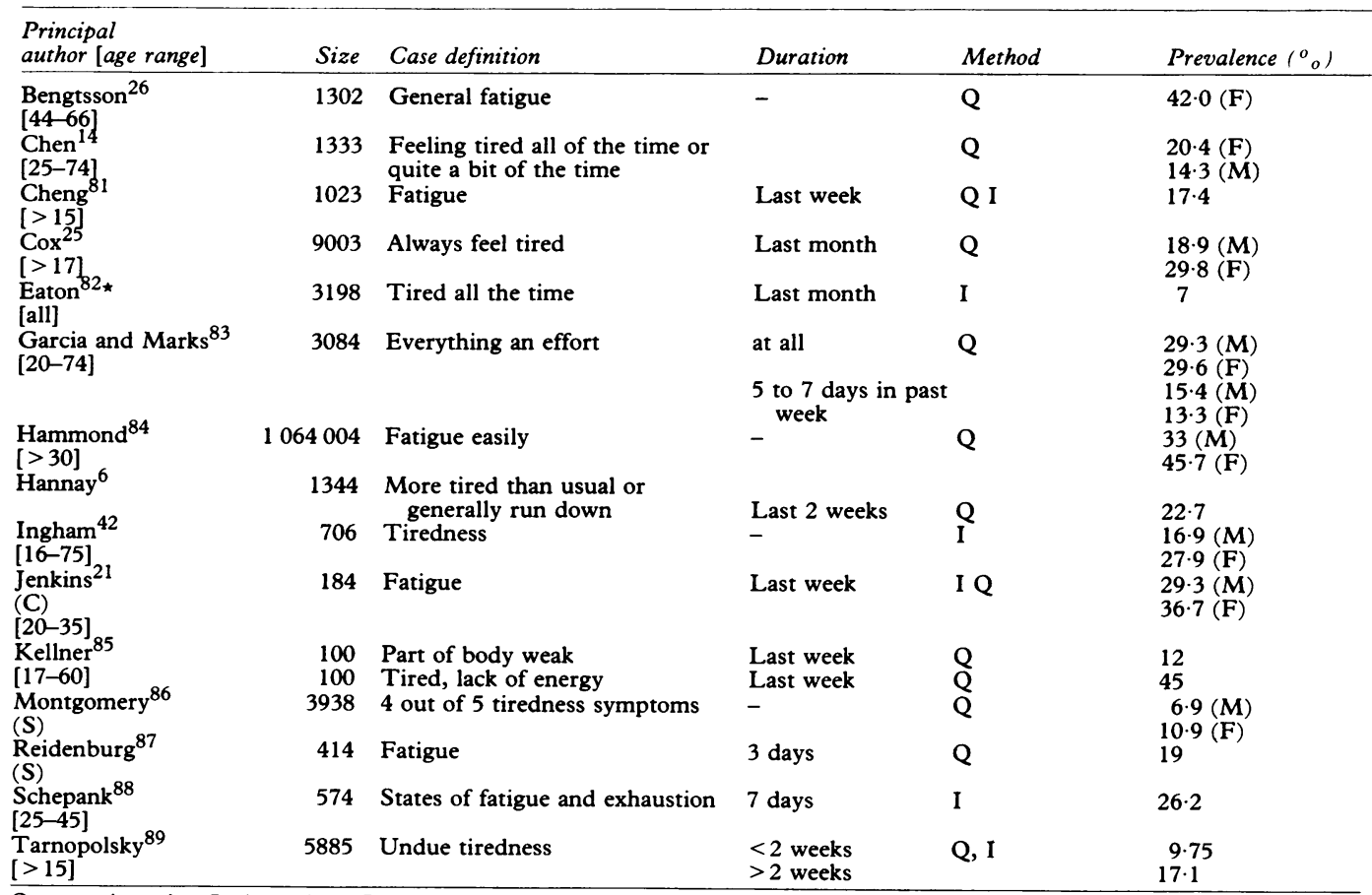

$\mathrm{Q}=$ questionnaire; $\mathrm{I}=$ interview; $\mathrm{C}=$ civil servants; $\mathrm{S}=$ students

* Fatigue attributed by interviewer to physical causes excluded

\begin{tabular}{|c|c|c|c|c|c|}
\hline $\begin{array}{l}\text { Principal } \\
\text { author [age range] }\end{array}$ & Size & Case definition & Duration & Method & Prevalence $\left({ }^{\circ}{ }_{0}\right)$ \\
\hline $\begin{array}{l}\text { Buchwald }{ }^{76} \\
{[17-50]}\end{array}$ & 500 & $\begin{array}{l}\text { Severe loss of energy or easy } \\
\text { fatigability, either constantly or } \\
\text { recurrently }\end{array}$ & $\begin{array}{l}\text { More than } 6 \\
\text { months }\end{array}$ & I & 21 \\
\hline David $^{9}$ & 611 & $\begin{array}{l}\text { Scores above } 9 \text { on Fatigue } \\
\text { Questionnaire }\end{array}$ & 3 months & Q & $\begin{aligned} 9 \cdot 0(\mathrm{M}) \\
12 \cdot 0(\mathrm{~F})\end{aligned}$ \\
\hline $\begin{array}{l}\text { Harding } \\
{[>15]}\end{array}$ & 1624 & Weakness as presenting complaint & - & $\mathrm{I}, \mathrm{Q}$ & $4 \cdot 7$ \\
\hline Ingham 42 & 709 & Tiredness & - & I & $\begin{array}{l}28 \cdot 5(\mathrm{M}) \\
44.6(\mathrm{~F})\end{array}$ \\
\hline${ }_{[>17]}$ & 1159 & Fatigue a major problem & $\begin{array}{l}\text { More than } 1 \\
\text { month }\end{array}$ & Q & \\
\hline Morrison ${ }^{45}$ & 31000 & $\begin{array}{l}\text { Fatigue unexplained after initial } \\
\text { interview }\end{array}$ & - & $\mathbf{R}$ & $\begin{array}{r}6.9(\mathrm{M}) \\
16.8(\mathrm{~F})\end{array}$ \\
\hline $\begin{array}{l}\text { Nelson }{ }^{41} \\
{[>17]}\end{array}$ & 1227 & Fatigue main complaint & 1 year & $\mathbf{R}$ & $9 \cdot 2$ \\
\hline Shepherd ${ }^{39}$ & 1683 & $\begin{array}{l}\text { Frequent episodes of complete } \\
\text { exhaustion and fatigue }\end{array}$ & - & Q & $\begin{array}{l}10 \cdot 7(\mathbf{M}) \\
18 \cdot 0(\mathrm{~F})\end{array}$ \\
\hline $\begin{array}{l}\text { Sugarman } \\
{[>15]}\end{array}$ & 6000 & Fatigue & - & $\mathbf{R}$ & $9 \cdot 9$ \\
\hline $\begin{array}{l}\text { Valdini } \\
{[>17]}\end{array}$ & 254 & Below 14 on Rand Vitality Index & - & Q & 45 \\
\hline
\end{tabular}




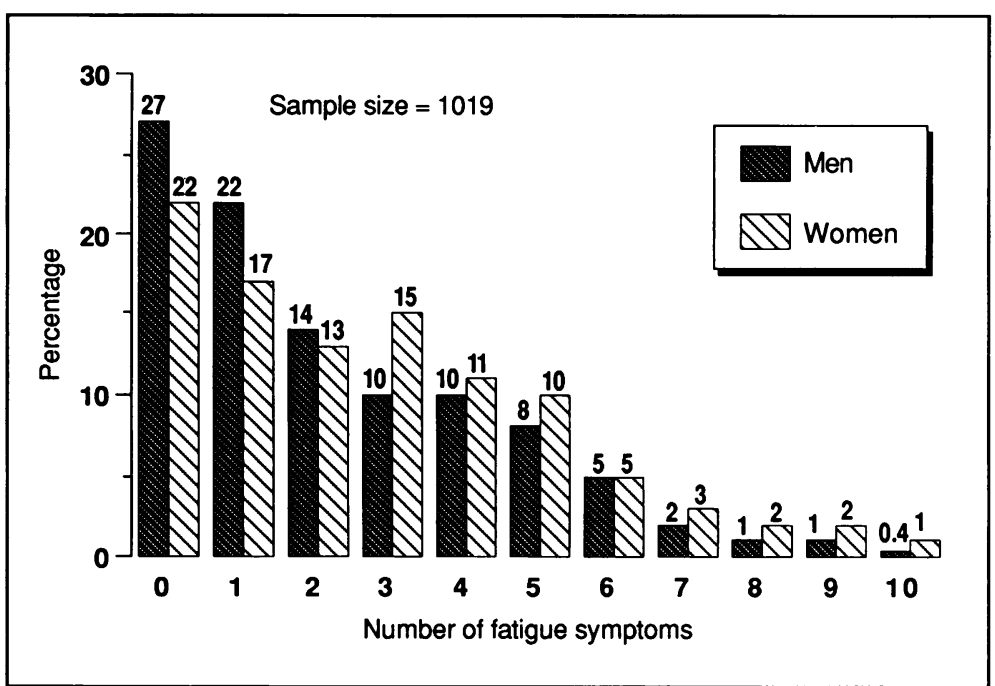

Histogram of the number of reported fatigue symptoms from the US General Social Survey. fatigue was a frequent reason for general practitioner consultation. The same study showed that fatigue and tiredness were usually chronic complaints, rather than short term discomforts, while Morrell reported that although fatigue was the second commonest symptom in a sample of females, it was an unusual reason for medical consultation. ${ }^{43}$ It is also clear that for most of these patients diagnoses other than fatigue are made-since although around 10 to $30^{\circ}{ }_{o}$ of those attending primary care have significant fatigue lasting more than a few weeks, it is recorded as a "diagnosis" in only $1-2 \%$ of primary care consultations. ${ }^{24}$ 44-46

What diagnoses are made? Further investigation of chronic fatigue in primary care shows that history taking and physical examination are more useful than laboratory tests in the assessment of chronic fatigue (C R Cloninger, personal communication, and ${ }^{47}$ ), and the doctor is most likely to presume a psychosocial cause. A separate study found that detailed physical examination and laboratory testing contributed to the diagnosis in $8.5^{\circ}{ }_{0}$ of chronically fatigued patients, while a psychiatric interview was instrumental in establishing a diagnosis in $73.5 \% \cdot{ }^{48}$ The probability of a psychiatric diagnosis increases with both the duration of fatigue and the number of associated symptoms. ${ }^{4950}$ However, it must be emphasised that psychiatric diagnoses, while important for treatment and prognosis, do not currently provide much evidence on the aetiology of the fatigue. Furthermore, in a study of 2225 attendances in primary care in the United Kingdom, although fatigue was five times more common in those with major depression than in those free of psychiatric disorder, it was neither a characteristic nor a discriminating symptom of mood disorder. ${ }^{51}$

Thus epidemiological and clinical studies of persistent fatigue in primary care conclude that the symptom is common, usually associated with psychosocial variables, and that detailed physical investigation is rarely indicated. These conclusions are neither disputed nor controversial, yet there is a certain reluctance to accept their implications when considering hospital based studies of chronic fatigue.

\section{Fatigue and primary care}

In the first systematic United Kingdom study of psychiatric illness in general practice, ${ }^{39} 16 \%$ of males and $24 \%$ of females admitted to rising in the morning feeling tired and exhausted. In the USA, $24 \%$ of those attending a primary care clinic regarded fatigue as a major problem, with a mean duration of 3.3 years $^{40}$ (table II). Fatigue is not just a frequent complaint in primary care (table II): it is also an important public health problem, as it is associated with disability comparable to that found in chronic medical patients. ${ }^{4041}$

How is fatigue related to the decision to consult a doctor? One approach to answering this question is to compare the prevalence of fatigue in primary care attenders and in the community. Only one study has used a similar case definition in the two settings. ${ }^{42}$ The primary care attenders had a higher prevalence of fatigue, which was also both more severe and more distressing. However, it would be wrong to conclude that the onset of
Selection bias in hospital case-control studies

Many hospital based studies have attempted to answer the current questions concerning CFS but have created more, rather than less, controversy. For example, studies using modern methods of psychiatric assessment generally confirm the findings of Allan in 1944,52 that the majority of hospital cases of CFS fulfil criteria for psychiatric illness, ${ }^{853-56}$ and that further physical investigation of those with chronic fatigue is rarely helpful. 5758 Alternatively, others have reported that the majority have immune dysfunction, ${ }^{59}$ persistent viral infection, ${ }^{60}$ a The role of previous psychiatric disorder is similarly unclear: retrospective studies have reported rates to be substantially increased, 535664 slightly increased, ${ }^{8}$ or identical to controls. ${ }^{65}$ Such contradictory findings have prevented the history of allergy, ${ }^{61}$ or a mixture of the three. ${ }^{62} 63$ 
emergence of a consensus to parallel that encountered in primary care.

One explanation is the problem of comorbidity, Psychiatric illness can and often does coexist with physical illness, but such possibilities have largely been ignored by both physicians and psychiatrists, perhaps because the assessment of affect in the physically ill is notoriously difficult. ${ }^{66}$ There are also suggestions that psychiatric disorder may be associated with immune dysfunction and may follow viral infection. ${ }^{67}$ However, there remain genuine contradictions in the literature. How have these arisen?

Selection factors are probably the most important bias in these studies. For example, for many years hospital studies of CFS in its various guises have found an overrepresentation of higher social classes, with a particular excess of health service professionals, ${ }^{3}$ and continue to do so. ${ }^{68}$ In contrast the key symptom of fatigue shows the opposite socioeconomic gradient in the community. ${ }^{25}$ It has recently been suggested that the apparent positive social class bias in hospital studies is the result of differences in health care utilisation. ${ }^{69}$

Another important selection factor is the self diagnosis of patients with chronic fatigue. Between $80 \%$ and $100 \%$ of the patients reported in the current general hospital based studies have self diagnoses of physical illness, especially of postinfection syndromes. 8535556646570 In primary care about half of those attending with fatigue ascribe their symptoms to a physical cause, ${ }^{71}$ but very few had self diagnoses of "ME"/CFS or its equivalents, ${ }^{9}$ suggesting that such diagnoses increase the likelihood of referral to specialists. Such patients undoubtedly have chronic fatigue as a dominant complaint, but we agree that this does not necessarily imply the existence of "chronic fatigue as a syndrome sui generis". ${ }^{72}$

Much psychological illness goes unrecognised by the physician, and this may in turn influence referral and lead to variation between studies. ${ }^{39507374}$ For instance, depressed patients with more pronounced somatic symptoms, including fatigue, and without previous contact with mental health services, are more likely to be referred to physicians than mental health specialists. ${ }^{75}$

Finally, referral could be influenced by exposure to infection, as physicians will refer those with fatigue and a history of infection, which could be coincidental, to centres interested in "post-viral fatigue" or "chronic EBV infection". A similar problem will occur if cases are recruited from self help organisations. This phenomenon will lead to an overestimate of any associations between infection and CFS, and was one of the reasons for disenchantment with the possible aetiological role of the Epstein Barr virus in CFS. ${ }^{76}$

These possible sources of bias illustrate the difficulty of conducting valid case-control studies on highly selected groups of patients with CFS.

\section{Fatigue syndromes-a diagnosis of exclusion?}

Several problems have been highlighted in the definitions of fatigue syndromes. Current definitions exclude those with an adequate medical explanation of fatigue, ${ }^{12}$ but what constitutes an "adequate" explanation? Though physicians can often exclude physical causes, the role of psychiatric illness is less often acknowledged. Some definitions of CFS also exclude those with psychiatric disorders, ${ }^{12}$ yet studies previously cited in secondary and tertiary referral centres usually find a high prevalence of psychiatric disorder among those with CFS, confirming that physicians are poor at detecting such disorders.

We conclude that the approach of excluding people with physical and psychiatric conditions is first impractical, second premature, especially since the causes of many psychiatric disorders remain obscure, and finally at odds with the common epidemiological approach that assumes a multifactorial aetiology. Physical and psychiatric conditions may increase the risk of fatigue independently of each other and hence patients with both conditions may be more likely to complain of tiredness. There is now a growing realisation that attempting to tease out multifactorial aetiologies will not be aided by excluding the psychiatrically ill from samples of CFS, ${ }^{77} 78$ though that group of patients with persistent fatigue who have neither recognisable physical illness nor psychiatric illness may also prove a valuable one to study in more detail. Pursuing the analogy with hypertension, where renal or endocrine causes do occur, discrete causes of CFS will continue to be discovered, but these must be seen in the overall context of the epidemiology of chronic fatigue, which will probably have a multifactorial aetiology. A hospital clinic may be an appropriate setting for studies of unusual causes of hypertension, but would give a misleading impression of the epidemiology and public health importance of elevated blood pressure-similar dangers attach to the current reliance on selected studies of CFS.

\section{Conclusions}

In the Washington Heights survey, ${ }^{79}$ doctors and patients were found to regard different symptoms with differing degrees of concern. "Feeling weak all over for much of the time" was regarded as "very serious" by only $6 \%$ of psychiatrists and $9 \%$ of physicians, making it one of the least important of $\mathbf{4 3}$ listed symptoms. In contrast, the non-professional samples regarded the same symptom as one of the most important of those listed.

Such opposite reactions between patients and professionals may account for some of the dissatisfaction that results from the encounters between patients with chronic fatigue and their doctors, and is so tellingly detailed in the many accounts by sufferers. It may also explain why the epidemiology of this important source of morbidity has been so neglected. The lack of systematic data and the unanswered questions illustrated in this article should be a reminder for physicians and epidemiologists to study morbidity as well as mortality. Fatigue does not kill but it is common, disabling, and is regarded as a serious symptom by our patients, who may be victims of a variant of Tudor Hart's inverse care law $^{80}$-an 
inverse interest law-that the commoner a condition the less the professional interest. Perhaps the current prominence of "ME" and the media criticism of the medical response to the problem is the response of the patient who has been ignored for too long.

GHL is supported by the Department of Health, SCW by a Wellcome Training Fellowship in Epidemiolgy.

1 David A, Wessely S, Pelosi A. Post-viral fatigue: time for a new approach. BMf 1988; 296: 696-9.

2 Muscio B. Is a fatigue test possible? Br f Psychology 1921; 12: $31-46$.

Wessely $S$. Old wine in new bottles: neurasthenia and "M.E." Psychol Med 1990; 20: 35-53.

4 May J, Kline P. Problems in using an adjective checklist to measure fatigue. Personality Individual Differences 1988; 9: 831-2.

5 Feinstein A. Clinical judgement. Baltimore: Williams and Wilkins, 1967: 315

6 Hannay D. Symptom prevalence in the community. $\mathcal{F} R$ Coll Gen Pract 1978; 28: 492-9.

7 Tibblin G, Bengtsson C, Furunes B, Lapidus L. Symptoms by age and sex Scand 7 Primary Health Care 1990; 8: 9-17. 8 Wessely S. Powell R. Fatigue syndromes: a comparison of chronic "postviral" fatigue with neuromuscular and affective disorders. F Neurol Neurosurg Psychiatry 1989; 52: 940-8.

9 David A, Pelosi A, MacDonald E, et al. Tired, weak or in need of rest: a profile of fatigue among general practice attenders. BMF 1990; 301: 1199-202.

10 Pinard G, Tetreault L. Concerning semantic problems in psychological examination. In: Pichot P, ed. Psychological measures in psychopharmacology. Mod Probl Pharmacopsychiatry 1974; 7: 8-22.

11 Berrios G. Feelings of fatigue and psychopatholgy: a conceptual history. Compr Psychiatry 1990; 31: 140-51.

12 Holmes G, Kaplan J, Gantz N, et al. Chronic fatigue syndrome: a working case definition. Ann Intern Med 1988; 108: $387-9$.

13 Swartz $M$. The chronic fatigue syndrome-one entity or many? N Engl f Med 1988; 319: 1726-8.

14 Chen $M$. The epidemiology of self-perceived fatigue among adults. Prev Med 1986; 15: 74-81.

15 Wadsworth M, Butterfield W, Blaney R. Health and sickness: the choice of treatment. London: Tavistock, 1971.

16 Verbrugge L, Asione S. Exploring the iceberg: common symptoms and how people care for them. Med Care 1987; 25: 539-63.

17 US Department of Health and Human Services. Patterns of ambulatory care in internal medicine: the National Ambulatory Medical Care Survey. Hyattsville, Maryland: National Center for Health Statistics, Series 13, No 80, 1984.

18 Rose G, Barker D. What is a case? Dichotomy or continuum? $B M \mathcal{F}$ 1978; ii: 873-4.

19 Cloniger C. A systematic method for clinical description and classification of personality variants. Arch Gen Psychiatry 1987; 44: 573-88.

20 Pickering $G$. The nature of essential hypertension. New York: Grune and Stratton, 1961

21 Jenkins $R$. Sex differences in minor psychiatric morbidity. Psychol Med 1985; Monograph, suppl 7.

22 Wessely $\mathrm{S}$. The epidemiology of fatigue; evidence from a large national survey. MSc research report. London: large national survey. MSc research report. London:

23 Matthews D, Lane T, Manu P. Gender differences among patients with chronic fatigue (abstract). Clin Res 1989; 37 : patients

24 Office of Population Census and Surveys. Morbidity statistics from general practice: third national survey, 1981 1982. London: HMSO, 1985

25 Cox B, Blaxter M, Buckle A, et al. The Health and Lifestyle Survey. London: Health Promotion Research Trust, 1987.

26 Bengtsson C, Edstrom K, Furunes B, Sigurdsson J, Tibblin G. Prevalence of subjectively experienced symptoms in population sample of women with special reference to arterial hypertension. Scand $\mathcal{f}$ Primary Health Care 1987; 5 155-62.

27 Wessely S, Nickson J, Cox B. Symptoms of low blood pressure: a population study. BMF 1990; 301: 362-5.

28 Uhlenhuth E, Balter M, Mellinger G, Cisin I, Clinthorpe J. Symptom checklist syndromes in the general population. Arch Gen Psychiatry 1983; 40: 1167-73.

29 Ross C, Hayes D. Exercise and psychologic well-being in the community. Am ₹ Epidemiol 1988; 127: 762-71.

30 Valdini A, Steinhardt S, Jaffe A. Demographic correlates of fatigue in a university family health centre. Fam Pract 1987 4: 103-7.

31 Farmer M, Locke B, Moscicki E, Dannenberg A, Larson D, Radloff $\mathrm{L}$. Physical activity and depressive symptoms: the Epidemiol 1988; 128: 1340-51

32 Muller R, Nylander I, Larsson L, et al. Sequelae of primary aseptic meningoencephalitis: a clinical, sociomedical, electroencephalographic and psychological study. Acta electroencephalographic and psychologic.

33 Imboden J, Canter A, Cluff L. Convalescence from influenza: a study of the psychological and clinical influenza: a study of the psychological and c.
34 White P. Psychiatric illness following glandular fever. Abstract presented at the quarterly meeting of the Royal College of Psychiatry, Leeds, April 4th, 1989.

35 Straus S. The chronic mononucleosis syndrome. f Infect Dis 1988; 157: 405-12.

36 Imboden J. Psychosocial determinants of recovery. $A d v$ Psychosom Med 1972; 8: 142-55.

37 Salit I. Sporadic post-infectious neuromyasthenia. Can Med Assoc F 1985; 133: 659-63.

38 Wessley $\mathrm{S}$. The natural history of fatigue and myalgia syndromes. In: Sartorius N, et al, eds. Psychological disorders in general medical settings. Bern: Hans Huber, 1990: 82-97.

39 Shepherd M, Cooper B, Brown A, Kalton G. Psychiatric illness in general practice, 2nd edition. Oxford: Oxford University Press, 1981.

40 Kroenke K, Wood D, Mangelsdorff D, Meier N, Powell J. Chronic fatigue in primary care: prevalence, patient Chronic fatigue in primary care: prevalence, patient

41 Nelson E, Kirk J, McHugo G, et al. Chief complaint fatigue: Nelson E, Kirk J, McHugo G, et al. Chief complaint fatigue: a longitudinal study from the

42 Ingham J, Miller P. Symptom prevalence and severity in a general practice population. $\mathcal{F}$ Epidemiol Community Health 1979; 33: 191-8.

43 Morrell $\mathrm{D}$. Symptoms perceived and recorded by patients. $\mathcal{f}$ $R$ Coll Gen Pract 1976; 26: 398-403.

4 Morrell D. Symptom interpretation in general practice. $\mathcal{F} R$ Coll Gen Pract 1972; 22: 297-309.

45 Morrison J. Fatigue as a presenting complaint in family practice. $\mathcal{F}$ Fam Pract 1980; 10: 795-801.

46 Sugarman J, Berg A. Evaluation of fatigue in a family practice. $\mathcal{F}$ Fam Pract 1984; 19: 643-7.

47 Valdini A, Steinhardt S, Feldman E. Usefulness of a standard battery of laboratory tests in investigating chronic fatigue in adults. Fam Pract 1989; 6: 286-91.

48 Lane T, Matthews D, Manu P. The low yield of physical examinations and laboratory investigations of patients with chronic fatigue. Am f Med Sci 1990; 299: 313-8.

49 Clare A, Blacker R. Some problems affecting the diagnosis and classification of depressive disorders in primary care. illness in primary care settings. London: Tavistock, 1986: 7-26.

50 Goldberg D, Huxley P. Mental illness in the community. London: Tavistock Publications, 1980.

51 Blacker R, Thomas J. Diagnosing depressive disorder in general practice: a prospective study. Abstract presented a the Fourth Annual NIMH International Research Conference on the Classification and Treatment of Mental Disorders in General Medical Settings. Bethesda, Maryland, June 11 th-12th, 1990.

52 Allan F. The differential diagnosis of weakness and fatigue. $N$ Engl f Med 1944; 231: 414-8.

53 Kruesi M, Dale J, Straus S. Psychiatric diagnoses in patients who have chronic fatigue syndrome. F Clin Psychiatry 1989 50: 53-6.

54 Manu P, Matthews D, Lane T. The mental health of patients with a chief complaint of chronic fatigue: a prospective evaluation and follow-up. Arch Intern Med 1988; 148: 2213-17.

55 Millon C, Salvato F, Blaney N, et al. A psychological assessment of chronic fatigue syndrome/chronic Epstein Barr virus patients. Psychol Health 1989; 3: 131-41.

56 Taerk K, Toner B, Salit I, Garfinkel P, Ozersky S. Depression in patients with neuromyasthenia (benign Depression in patients with neuromyasthenia (benign myalgic

57 Harvard C. Lassitude. BMF 1985; 290: 1161-2.

58 Kroenke $\mathrm{K}$, Mangelsdorf $\mathrm{D}$. Common symptoms in ambulatory care: incidence, evaluation, therapy and outcome. Am F Med 1989; 86: 262-6.

59 Lloyd A, Wakefield D, Broughton C, Dwyer J Immunological abnormalities in the chronic fatigue syndrome. Med 7 A A st 1989; 151: 122-4.

60 Yousef G, Bell E, Mann G, et al. Chronic enteroviru infection in patients with postviral fatigue syndrome. Lancet 1988; i: 146-50.

61 Straus S, Dale J, Wright R, Metcalfe D. Allergy and the chronic fatigue syndrome. $\mathcal{F}$ Allergy Clin Immunol 1988; 81 791-5.

62 Behan $\mathrm{P}$, Behan $\mathrm{W}$, Bell E. The postviral fatigue syndrome-an an

63 Komaroff A. Chronic fatigue syndromes: relationship to chronic viral infections. F Virol Methods 1988; 21: 3-10.

64 Gold D, Riggs R, Katon W, Ashley R, Obrigewitch R, Corey L. Chronic fatigue: a prospective clinical and virologic study. $¥ A M A$ 1990; 264: 48-53.

65 Hickie I, Lloyd A, Wakefield D, Parker G. The psychiatric status of patients with chronic fatigue syndrome. $B r F$ Psychiatry 1990; 156: 534-40.

66 Ray C. Chronic fatigue syndrome and depression conceptual and methodological ambiguities. Psychol Med 1991; 21: 1-9.

67 Kurstak E, Lipowski Z, Morozov P, eds. Viruses, immunity and mental disorder. London: Plenum 1987.

68 Dowsett E, Ramsay A, McCartney R, Bell E Myalgic encephalomyelitis-a persistent enteroviral infection? Postgrad Med f 1990; 66: 526-30.

69 Wessely S, Price R, Robins L, et al. Epidemiology of fatigue: evidence from the United States and the United Kingdom. Abstract presented at the 118th Annual Meeting of the American Public Health Association, New York, Sept 30th 1990. 
70 Matthews D, Manu P, Lane T. Diagnostic beliefs among patients with chronic fatigue (abstract). Clin Res 1989; 37 $820 \mathrm{~A}$.

71 Kirk J, Douglass R, Nelson E, et al. Chief complaint of fatigue: a prospective study. $\mathcal{F}$ Fam Pract 1990; 30: 33-41. 72 Denman A The chronic fatigue syndrome: a return to common sense. Postgrad Med F 1990; 66: 499-501.

73 Goldberg D, Reasons for misdiagnosis. In: Sartorius N, Goldberg D, di Girolamo G, Costa e Silva J, Lecrubier Y, Wittchen $\mathrm{H}$, eds. Psychological disorders frequently encountered in medical settings. Bern: Hans Huber, 1990: $139-45$.

74 Clare A, Blacker $R$. Some problems affecting the diagnosis and classification of depressive disorders in primary care. In: Shepherd M, Wilkinson G, Williams P, eds. Mental illness in primary care settings. London: Tavistock, 1986: 7-26.

75 Dew M, Dunn L, Bromet E, Schulberg H. Factors affecting help-seeking during depression in a community sample. $\mathcal{F}$ Affective Disord 1988; 14: 223-34.

76 Buchwald D, Sullivan J, Komaroff A. Frequency of chronic active Epstein-Barr virus infection in a general medical practice. FAMA 1987; 257: 2303-7.

77 Komaroff A, Strauss S, Gantz N, Jones J. The chronic fatigue syndrome. Ann Intern Med 1989; 110: 407-8.

78 Sharpe M, Archard L, Banatvala J, et al. Chronic fatigue syndrome: guidelines for research. $\mathcal{F} R$ Soc Med 1991; 84: 118-21.

79 Dohrenwend B, Crandell D. Psychiatric symptoms in community, clinic, and mental hospital groups. Am $\mathcal{Y}$

80 Tudor Hart J. The inverse care law. Lancet 1971; i: 405-12.
81 Cheng T. Symptomatology of minor psychiatric morbidity: a cross cultural comparison. Psychol Med 1989; 19: 697708

82 Eaton W, Dryman A, Sorenson A, McCutcheon A. DSMIII major depressive disorder in the community: a latent class analysis of data from the NIMH epidemiologic catchment area programme. Br f Psychiatr 1989; 155 : 48-54.

83 Garcia M, Marks G. Depressive symptomatology among Mexican-American adults: an examination with the CES-D Scale. Psychiatr Res 1989; 27: 137-48.

84 Hammond E. Some preliminary findings on physical complaints from a prospective survey of $1,064,004 \mathrm{men}$ and women. Am F Public Health 1964; 54: 11-23.

85 Kellner R, Sheffield B. The one week prevalence of symptoms in neurotic patients and normals. Am $f$ symptoms in neurotic pa
Pychiatry 1973; 130: 102-5.

86 Montgomery G. Uncommon tiredness among college undergraduates. F Consult Clin Psychol 1983; 51: 517-25. 87 undergraduates. $f$ Consult Clin Psychol 1983; 51 : $517-25$. Engl ₹ Med 1968; 279: 678-9.

88 Schepank H. Epidemiology of pyschogenic disorders: the

89 Tannopolsky A, Watkins G, Hand D. Aircraft noise and mental health: 1. Prevalence of individual symptoms Psychol Med 1980; 10: 683-98.

90 Harding T, De Arango M, Baltazar J, et al. Mental disorders in primary health care: a study of their frequency and diagnosis in four developing countries. Psychol Med 1980 10: $231-41$.

91 Valdini A, Steinhardt S, Valicenti J, Jaffe A. A one year follow up of fatigued patients. 7 Fam Pract 1988; 26: 33-8. 